\title{
Saneamiento territorial y Seguridad: Grandes pendientes en las acciones institucionales a 10 años del proceso de lucha por la recuperación del territorio de Salitre
}

\begin{abstract}
Mariana Delgado Morales Costarricense. Lideresa en la lucha por la recuperación del territorio de Salitre, agricultora, hablante de bribri.

Ella ha sido parte de la

Asociación de Desarrollo Integral de Salitre, así como

también del Comité de

Caminos y la Junta de

Educación. Actualmente es investigadora comunitaria del

Centro de Investigación en Cultura y Desarrollo (CICDE) en el Programa Cultura Local

Comunitaria y Sociedad Global (PROCULTURA).
\end{abstract}

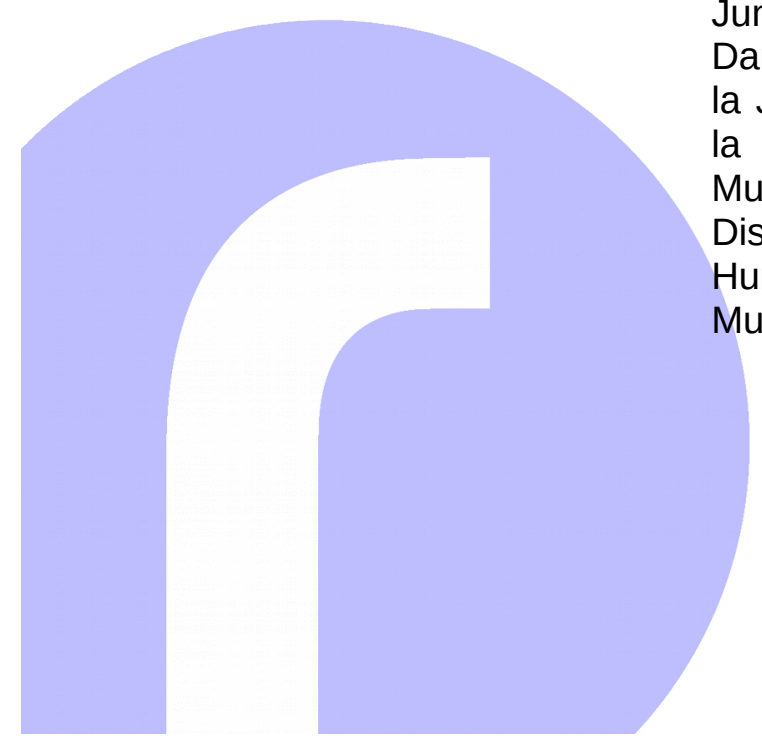

https://revistas.uned.ac.cr/index.php/rupturas (c) (1) (2)
Esta ponencia de Mariana Delgado Morales, investigadora bribri del Centro de Investigación en Cultura y Desarrollo, de la Universidad Estatal a Distancia (UNED), mujer bribri recuperadora de territorio, integrante del Consejo Ditsö Iriria Ajkunuk Wakpa de Salitre, se realizó en el panel: Territorio y violencia en Salitre: Diez años de luchas indígenas y acciones institucionales, organizado por el CICDE y realizado el día miércoles 28 agosto en el Paraninfo Daniel Oduber en la Sede Central, en Mercedes de Montes de Oca.

Este panel es parte de un proyecto de reflexión más amplio del CICDE que se llevó a cabo durante el segundo semestre de este 2019, que consistió de un ciclo de actividades sobre temas de importancia coyuntural para el país, al cual hemos llamado: Hacia el $10^{\circ}$ aniversario del CICDE y el Bicentenario de Costa Rica.

Junto a Mariana participaron como ponentes: la Dra. Damaris Vargas Vásquez de Subcomisión de Acceso a la Justicia de Pueblos Indígenas del Poder Judicial de la República de Costa Rica; la MSc. Xinia Zúñiga Muñoz, investigadora de la Universidad Estatal a Distancia; Suy Wong del Observatorio de Derechos Humanos y Autonomía Indígena ODHAIN, y Diana Murillo Murillo, Gerenta General del INDER. 
Saludos de parte del Pueblo Bribri de Salitre. Es un orgullo compartir con ustedes este espacio que se me brinda para dar a conocer el Territorio Bribri de Salitre.

Estamos ubicados en la zona sur del país a cinco kilómetros del Centro del cantón central Buenos Aires. Con una extensión de 11700 hectáreas y más de mil habitantes indígenas Bribris.

Haré una pausa en este momento y referiré con tristeza al atroz incendio, el cual acaba con poblados indígenas y miles de especies animales, hablo de la Amazonía, lugar ancestral, que al igual que nosotros lucha en contra de los intereses gubernamentales y acciones que provocan muertes, para ellos y ellas, hermanos indígenas mis conmiseraciones al respecto, porque sé de esa lucha en la cual viven y sobreviven todos los días. Mi respeto.

Bien, el Concejo Ditsö Iriria Ajkunuk Wakpa, tiene sus inicios desde el año 1979, llamado Concejo de Awa, para los años 2000 cambia su nombre al actual, legalmente constituido según el derecho consuetudinario, respaldado por el Convenio 169 de la OIT, ratificado en nuestro país, "un país de derecho", quien no aplica dicho instrumento jurídico.

Menciono la Amazonia, porque aquí en Costa Rica hay una Amazonía, con 24 territorios indígenas y 8 etnias en peligro de extinción, y el fuego abrasador de nuestro Gobierno que pasa desapercibido e ignora aun sabiendo la problemática de cada uno.

A pesar de ese fuego abrazador de los Gobiernos de turno, en muchos años, el Concejo Ditsö mantiene sus principios ancestrales, y los objetivos: Gobernanza y Reivindicación de Tierras, con claros fundamentos basados en la cosmovisión bribri.

Ha logrado que los indígenas Bribris hayan recuperado el $80 \%$ del Territorio Indígena Bribri de Salitre, en recuperaciones de hecho pacíficas, de manos de terratenientes no indígenas. Este proceso ha costado sangre y muerte de compañeros, que han sido agredidos, macheteados, marcados cual fuesen ganado, también han sufrido discriminación de parte de entes del gobierno y sus funcionarios, quienes a la hora de defendernos nos menosprecian.

Muerte, asesinato que sufrió nuestro querido hermano Sergio Rojas Ortiz, hijo de una madre indígena bribri, del clan Uniwak, por pertenecer, y ayudar a todos nosotros sus hermanos indígenas Bribris de Salitre, por creer y considerar el derecho único de los Bribris sobre el Territorio Bribri.

Estos hechos de violencia nos hacen recurrir a la Corte Interamericana de Derechos Humanos de la ONU, la cual dicta Medidas Cautelares para el Pueblo Bribri de Salitre, MC-321-12, aun, sin embargo, nuestro hermano, padre, amigo Sergio Rojas Ortiz, es asesinado. Y a casi seis meses, el Ministerio Judicial, ni tampoco el Ministerio de la Presidencia, han esclarecido su asesinato. 
La reivindicación de la tierra es parte esencial de los objetivos que como Concejo perseguimos día con día. Sergio Rojas Uniwak, mediante derecho consuetudinario legal, según nuestra cosmovisión, a la cabeza del ADI en 2010, emprende una dura lucha en contra de los terratenientes y el Gobierno de turno, mi persona en la junta directiva emprendemos la lucha legal de los Desalojos, a los cuales los Contenciosos Administrativos, judiciales, penales, convencionales salen a relucir. En el Gobierno de Solís no se logra nada, el Gobierno entrante de Alvarado se hizo presente, porque se tuvo que perder la vida Don Sergio Uniwak para lograr retomar la presión de las Medidas Cautelares MC 321-12, de la Corte interamericana de Derechos Humanos de la ONU.

Luego de cuatro reuniones con el actual gobierno, debido al protocolo de acción para implementar estas medidas cautelares, no se logra concretar nada aun, al contrario, nos violentan al ejecutar algunos desalojos, y dar el derecho de posesión que le dio el Estado a las ADI, sobre el derecho consuetudinario del Concejo Ditsö, pero ya sabemos también de la imposición del Estado ha estado presente mediante las ADI, y su coraza de ejercer lo legal, según las leyes de Costa Rica.

No entiendo, seguro porque no tengo ese pensamiento neoliberal-capitalista, mantengo mi pensamiento ancestral con respecto a la relación con la madre tierra.

No comprendo, tras cuatro conversaciones con el Estado, su burocracia retrocede los procesos, puesto que las demandas en contra de los hermanos indígenas no avanzan, y cuando avanzan la complicidad de esos efectos burocráticos no permiten que las tierras vuelvan a manos de indígenas por la simple razón de que no existe buena voluntad de parte del Poder Judicial, en busca un proceso simplificado de estos proceso judiciales, hablamos de más de cien procesos judiciales en contra de los hermanos cuidadores de la Tierra, a veces cada uno con diez procesos judiciales, pero al contrario, estos procesos burocráticos se convierten en aspectos negativos en contra de los indígenas Bribris. Necesaria y urgentemente se debe de pensar en un proceso simplificado donde los Jueces, Defensores Públicos, sepan y conozcan la realidad del pueblo indígena bribri, tener paciencia inagotable a la particularidad del idioma, su pensamiento es otro ligado al cuido y reivindicación de la tierra, es un hecho, es un fenómeno natural, de particular de cada indígena bribri.

No comprendo cómo hay un proceso burocrático, que no condena a un no indígena usurpador de nuestra tierra que envenena nuestras aguas, no comprendo cuando rocían veneno sobre la cara de una hermana indígena, estos procesos burocráticos permiten que los verdaderos culpables estén todavía en nuestras tierras, amenazando de muerte a los nuestros, y el Poder Legislativo no se pronuncie. A la vez, pienso en el asesinato de nuestro hermano Sergio Rojas, no esclarecido aun después de casi seis meses.

Ahora bien, el Gobierno se sienta a "dialogar" entre comillas, más bien pienso que se sienta por un deber, una exigencia, pero no se ven resultados concre- 
tos a favor del pueblo bribri de Salitre, un solo ejemplo es la determinación de los actuales desalojos traspasados a la actual Asociación Indígena Bribri de Salitre, que no tiene como objetivo los desalojos, despojándonos del derecho consuetudinario que como indígenas Bribris tenemos al Territorio Indígena Bribri de Salitre, ¡Es de los Bribris!

Ahora hablaremos de saneamiento territorial. Con este gobierno de turno. empezando desde cero, solo con el protocolo firmado y aprobado para ejecutar las medidas cautelares MC 231-12

\section{Saneamiento}

La respuesta del Gobierno a la recuperación de nuestros territorios es el PLAN RTI. Analizando este dichoso plan encontramos los siguientes problemas:

-EI PLAN RTI es solo otro estudio territorial, no es plan o un mandato de desalojar (como los numerosos estudios territoriales, históricos, previos de Salitre, Térraba y otros territorios indígenas). El Estado nunca tomó los resultados de estos estudios previos para implementar medidas para sanear nuestros territorios. ¿Porque debemos tener confianza que esta vez es diferente? La "buena fe" en la que se fundamenta el ESTADO, es que se han acercado a dialogar, pero no ha ocurrido nada extraordinario que no sepamos, que no esperemos, más bien le da la custodia legal a la ADI, con lo que no estamos de acuerdo, esto es una de las muchas "puñaladas" que hemos recibido por parte del Estado. Que su burocracia está por delante, pues queremos indicar que no estamos de acuerdo, y ellos lo saben y no hacen por donde mejorarlo. Volviendo al tema.

-EI PLAN RTI no define qué pasa con los resultados del estudio (según el texto del Plan, los resultados son los expedientes que van a producir). El Plan no explica, quien tendrá la responsabilidad de iniciar procesos para convertir estos expedientes a órdenes de desalojos. ¿La Fiscalía, la ADI, el Ministerio de Seguridad Pública?, no sabemos porque el PLAN RTI no dice, no está detallada en el Plan el proceso que el Estado seguirá después de que INDER produce los resultados de sus estudios. Esto es una enorme brecha en el Plan y muy problemático.

-EI PLAN RTI también no explica como su proceso complementará y no perjudicará las investigaciones y procesos más avanzados de la Fiscalía (a menos con respeto a Salitre). ¿Cuál es la relación de uno a otro? El Estado no nos ha garantizado que los dos procesos no tendrán conflicto entre cada uno, por ejemplo, llegando a conclusiones diferentes.

Esto es problemático, especialmente porque el texto del PLAN RTI dice que INDER debe hacer su trabajo a partir de los estudios previos y las investigaciones de la Fiscalía, es decir, en este proceso tendremos dos entes hablando de la misma cosa, con resultados muy cercanos a ser diferentes, ¿podre- 
mos confiar? La respuesta es no, nada de lo que pase nos mantendrá seguros de que no habrá un conflicto posterior, lo hemos visto porque no sugieren procesos simplificados.

-Más que esto, el Estado no ha explicado cómo van a resolver la problemática de las apelaciones a los órdenes de desalojo. La experiencia del Pueblo Bribri de Salitre es que en el momento que existe una orden de desalojo, el no indígena utiliza las cortes para apelar las decisiones y el desalojo está demorado por años. Si el Estado no ofrece una forma simplificada y especial de procesar estas apelaciones, no solo acorde a los derechos de debido proceso, pero consistente con los derechos de los pueblos indígenas, no vamos a ver desalojos por muchos años, es más apelan y apelan estos procesos, y nuevamente se atrasa.

-Además, a pesar de nuestras gestiones, el Estado no ha aceptado de acelerar el desalojo de fincas priorizadas por nosotros. Que pasa con los no indígenas que profesan odio, violencia, muerte y amenazas? El Estado quieren que nosotros tengamos paciencia, ya antes mencioné que recibimos muerte, envenenamiento, encaramiento de los nuestros con ellos, asesinato de un hermano, ¿qué se espera? ¿Una muerte más, o qué? esperando que los estudios realizados a estas fincas estén finalizados en todo el territorio, antes de realizar acciones contra ni siquiera un ocupante no indígena. Esto puede tomar mucho tiempo y no es la forma, y ya lo comentamos. Más que esto, el texto del PLAN RTI expresamente permite esta priorización. Los Bribri negociaron este texto. Entonces, insistimos que en cada territorio indígena el INDER negocie con los pueblos sobre la forma de lograr el PLAN, incluso por priorizar ciertas fincas como muestras de "buena fe" y como forma de calmar la violencia en el territorio en un corto plazo. Un ejemplo, son los hermanos y hermanas de la recuperación kapliña en la comunidad de Puente, que se encuentran, al otro lado de la cerca, en la ronda del camino.

-Otro problema: el Estado no ha solucionado el problema de la ADI. Como vimos durante las deliberaciones sobre el Proyecto de la Ley de Autonomía, mayormente los pueblos indígenas han rechazado la institución de la ADI. Hay pocos territorios indígenas que tienen ADI que respetan y luchan para los derechos indígenas en sus territorios, al contrario, funcionan para el beneficio de los usurpadores e intereses no indígenas. Sin embargo, cuando los desalojos de no indígenas están ejecutados por el Estado (como los Bribri recién han visto), la posesión de la parcela está firmada/entregada a la ADI que puede seguir otorgando certificaciones de posesión a no indígenas y favoreciendo los miembros que son afiliados. Hasta que la ley interna de Costa Rica y las políticas del Estado respeten la autogobernanza de los pueblos en nuestros territorios, reconociendo el poder y personaría jurídica de nuestras instituciones tradicionales, nunca tendremos un verdadero saneamiento. No hay confianza en los ADIs y las normas internas de Costa Rica dicen que son ellos que cuentan con los títulos a nuestras tierras.

-Además, no hay garantías que INDER no contará con el apoyo y consejo de las autoridades tradicionales no legitimas (como la Autoridad Tradicional de los Bribri, organizado por personas que apoyen los intereses de los 
no indígenas, famosa por otorgar certificaciones falsas de pertenencia étnica indígena, y una organización desvirtuada por la Corte nacional). Tenemos pruebas que INDER está aliando con algunas de estas autoridades no legítimas para determinar quién es y no es indígena. Esto tiene que parar.

-Adicionalmente, les informo sobre los dos desalojos ejecutados ya en Salitre hace unos meses. Fueron dos fincas recuperadas previamente por los Bribri. Esperamos el cumplimiento de las promesas del Estado de ejecutar los otros 6 desalojos administrativos existentes, actualmente retirando no indígenas. Además, notamos que, en estas dos propiedades sujetas a la ejecución de los desalojos, el Estado no saneó la propiedad. Entraron nuevos usurpadores en los últimos dos años. El Estado los dejó, no los retiraron. El Estado solo nos avisó que el pueblo tiene que presentar otra solicitud de desalojo para remover estos nuevos invasores no indígenas. Esto señala un problema con nuestro presunto "Estado de Derecho". La ley guiando el deber del Estado de sanear nuestros territorios permite un círculo vicioso que no pone fin a la usurpación y ocupación masiva a nuestros territorios. El Estado necesita reformar el sistema de judicial, en estos casos, si realmente quieren demostrar respeto por nuestros derechos y proteger a nuestra gente de violencia. Esperamos una gestión del Estado que está dispuesto a estas reformas.

\section{Seguridad}

Finalmente, respecto a la violencia (con la ocupación masiva siendo la causa subyacente), primero: la alta presencia de policía ayuda, pero no es la solución. La solución es el saneamiento final es el retiro de los no indígenas. Mientras esto no ocurra, el Estado tiene que protegernos.

Como conocen ustedes desde 2015, los Bribri (con sus co-beneficiarios, los Brörán) tienen Medidas Cautelares de la Comisión Interamericana de Derechos Humanos. Su falta de implementación por el Estado permitió el ambiente que posibilitó el asesinato de Sergio.

Siguen las amenazas de muerte contra nuestros hermanos y hermanas, Doña Magdalena tiene el privilegio de Sibö de seguir viva, porque un usurpador le roció la cara con veneno, al principio de este mes ocurrió este hecho, anteriormente la fuente de agua de Juan de la Cruz en Di sie, Río Azul, fue envenenada como presión para desistir de su derecho sobre su tierra, hechos que tienen menos de dos meses, entonces quien nos explica como proceden esos hechos violentos.

Saben, el Pueblo Bribri de Salitre enfrenta por semana al menos dos denuncias, con dos defensores públicos, de los cuales uno no es de nuestra confianza porque lo vemos muy relacionado con los casos de los no indígenas, no conoce los derechos de los pueblos indígenas. No conoce de la realidad del Pueblo Bribri de Salitre, puesto que están muchas veces a favor del no indígena. 
Por otro lado, la protección a las víctimas. Otro ejemplo, ya existen, desde antes que a Sergio lo asesinaran, ¿de qué nos sirvió?, de nada, no es un proceso de protección eficiente según como ellos lo plantean, además que los miembros de la policía nos desprecian porque tiene que embarrialarse para ir por nuestras firmas, no es seguro, no es eficaz, no es continuo, no nos sirve. Hay violencia y no ha sido erradicada.

Muchas otras cosas más podemos compartir, este discurso será no grato para muchos, en especial para el Estado. Pero esto es solo parte de la realidad del Pueblo Bribri de Salitre, que sangra cada día, enfrentándonos a un gran Wimbrö, todos los días que es precisamente el Estado y su burocracia.

Pablo Presbere dijo: Hoy moriré, pero resucitaré en miles... hoy hemos resucitado no precisamente con alegría, hoy no nos acompaña otra vez Sergio Uniwak, querido hermano Bribri. A él, el Pablo Presbere del 2019. A él la lucha en la cual creímos muchos, y muchos queremos justicia verdadera.

Sergio, vive... la Lucha Sigue, Autonomía, Tierra y Resistencia.

A todos los hermanos mi respeto, y gracias a aquellos que han creído también en lo nuestro. La Tierra...

Mil Gracias.... 